\title{
Efficacy and Effectiveness of Physical Agent Modalities in Complex Regional Pain Syndrome Type I: A Scoping Review
}

\author{
Antimo Moretti ${ }^{1, *(1)}$, Francesca Gimigliano ${ }^{2}\left(\mathbb{D}\right.$, Marco Paoletta ${ }^{1}$, Sara Liguori ${ }^{1}$, Giuseppe Toro ${ }^{1}$, \\ Milena Aulicino ${ }^{1}$, Stefano Conversano ${ }^{1}$ and Giovanni Iolascon ${ }^{1}$ \\ 1 Department of Medical and Surgical Specialties and Dentistry, University of Campania "Luigi Vanvitelli", \\ 80138 Naples, Italy; marco.paoletta@unicampania.it (M.P.); sara.liguori@unicampania.it (S.L.); \\ giuseppe.toro@unicampania.it (G.T.); milena.aulicino@studenti.unicampania.it (M.A.); \\ stefano.conversano@studenti.unicampania.it (S.C.); giovanni.iolascon@unicampania.it (G.I.) \\ 2 Department of Mental and Physical Health and Preventive Medicine, University of Campania "Luigi \\ Vanvitelli", 80138 Naples, Italy; francesca.gimigliano@unicampania.it \\ * Correspondence: antimo.moretti@unicampania.it; Tel.: +3-908-1566-5537
}

Citation: Moretti, A.; Gimigliano, F.; Paoletta, M.; Liguori, S.; Toro, G.; Aulicino, M.; Conversano, S.;

Iolascon, G. Efficacy and Effectiveness of Physical Agent Modalities in Complex Regional Pain Syndrome Type I: A Scoping Review. Appl. Sci. 2021, 11, 1857. https://doi.org/ 10.3390/app11041857

Academic Editor: René Schwesig

Received: 29 December 2020

Accepted: 17 February 2021

Published: 20 February 2021

Publisher's Note: MDPI stays neutral with regard to jurisdictional claims in published maps and institutional affiliations.

Copyright: (c) 2021 by the authors. Licensee MDPI, Basel, Switzerland. This article is an open access article distributed under the terms and conditions of the Creative Commons Attribution (CC BY) license (https:// creativecommons.org/licenses/by/ $4.0 /)$.

\begin{abstract}
Complex regional pain syndrome type I (CRPS-I) is a rare condition with huge variability in triggering factors and clinical scenarios. The complexity of the pathophysiology of this condition fosters the proposal of several therapeutic options with different mechanisms of action in both research and clinical practice. An interdisciplinary and multimodal approach, including pharmacological and non-pharmacological interventions, particularly physical therapy, is recommended by international guidelines, but the benefits and harms of available interventions are poorly known. In this scoping review, the clinical rationale for use of physical agent modalities for patients with CRPS-I will be presented. We found 10 studies addressing the role of electromagnetic field therapy, electrotherapy, and laser therapy. Our findings suggest that physical therapy modalities, in particular transcutaneous electrical nerve stimulation (TENS) and pulsed electromagnetic field therapy (PEMF), may contribute to reduce pain and improve function in patients with CRPS-1.
\end{abstract}

Keywords: physical therapy modalities; physical and rehabilitation medicine; rehabilitation; complex regional pain syndromes; reflex sympathetic dystrophy; electric stimulation therapy; laser therapy; low-level light therapy; magnetic field therapy; hyperthermia; induced

\section{Introduction}

Complex regional pain syndrome (CRPS) is a chronic pain condition consisting of localized spontaneous or evoked pain that usually affect one body extremity whose severity is disproportionate to the trigger event [1]. From a pathophysiological perspective, CRPS is a multifactorial disorder characterized by neurogenic inflammation, nociceptive sensitization, impaired vasomotor response and maladaptive neuroplasticity [2]. It affects from 5.46 to 26.2 out of 100,000 people per year [3].

The current classification divides CRPS into three types [4], where CRPS type I is significantly more frequent (about $90 \%$ of cases) than CRPS type II and CRPS-NOS (not otherwise specified) [5]. The division of CRPS into type I or reflex sympathetic dystrophy (RSD) and type II or causalgia depends on the absence or presence of identifiable nerve injury, respectively [6]. The main risk factors for CRPS-I are postmenopausal female gender, distal radius fracture, intra-articular fracture or ankle dislocation, exaggerated pain in the early phases after trauma, prolonged immobilization, and psychosocial issues [7]. Chronic pain, sensory abnormalities (allodynia or hyperalgesia), skin vasomotor alterations, sweating and motor changes are the most common signs and symptoms of CRPS-I [8] that are included in the "Budapest criteria", representing the gold standard for clinical diagnosis [9]. To date, a multidisciplinary approach including both pharmacological and non-pharmacological therapy is recommended. Among non-pharmacological treatment, 
physiotherapy should be considered to manage CRPS [10], both in adults and pediatric populations [11]. This intervention is commonly provided in a comprehensive approach that includes manual therapy, instrumental physical therapies, massage and therapeutic exercise [12]. Instrumental physiotherapy is a branch of rehabilitation that uses physical agents for therapeutic purposes. These approaches help to manage chronic pain associated with specific conditions [13], such as low back pain [14] and knee osteoarthritis [15], although their role in the treatment of CRPS-I is not well investigated. Furthermore, even less evidence about therapeutic parameters used to treat CRPS-I, such as intensity, duration, frequency and timing is available.

The aim of our review is to examine the current knowledge about efficacy and effectiveness of physical agent modalities for the treatment of patients with CPRS-I.

\section{Materials and Methods}

We performed a scoping review according to the PRISMA-ScR (Preferred Reporting Items for Systematic Reviews and Meta-Analyses Extension for Scoping Reviews) model [16].

Firstly, a technical expert panel (TEP) consisting of 8 physicians, including five pain rehabilitation specialists (G.I., F.G., A.M., M.A., S.C.), two experts in scoping review methodology (M.P., S.L.), and one orthopedic surgeon (G.T.), was established.

The TEP investigated the effects of the most used instrumental physical therapy modalities for CRPS-I: electric stimulation therapy, pulsed electromagnetic field (PEMF), low-level light therapy (LLLT), laser therapy, magnetic field therapy, extracorporeal shockwave therapy (ESWT), cryotherapy, and induced hyperthermia.

\subsection{Search Strategy}

The TEP organized a search strategy on PubMed (Public MedLine, run by the National Center of Biotechnology Information, NCBI, of the National Library of Medicine of Bethesda, Bethesda, MD, USA), with an ad-hoc search string with selected key words for CRPS combined with terms regarding physical therapy modalities (Table 1).

Table 1. Search Strategy

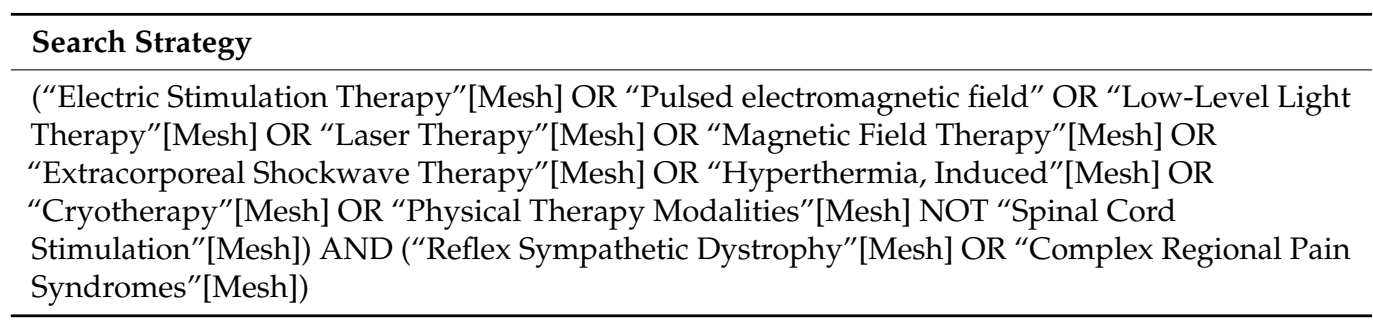

\subsection{Study Selection}

According to the objective of the present scoping review, the TEP outlined the characteristics of the sources of evidence, considering as inclusion criteria any research published in the scientific literature from inception to 31 October 2020 and including only those in the English language. The eligibility criteria are reported in Table 2.

\subsection{Data Extraction and Quality Assessment}

Basic researches and clinical studies written in English language from inception to 31 October 2020 were selected. All data were extracted from full texts. Results and findings from each included study were qualitatively analyzed. Then, we divided randomized controlled trials (RCTs) and observational studies to evaluate the efficacy and effectiveness of different interventions, respectively. Indeed, the efficacy is the performance of an intervention under ideal circumstances (as investigated in RCTs), whereas the effectiveness is a measure of the degree of effect of an intervention in clinical practice. 
Table 2. Eligibility criteria.

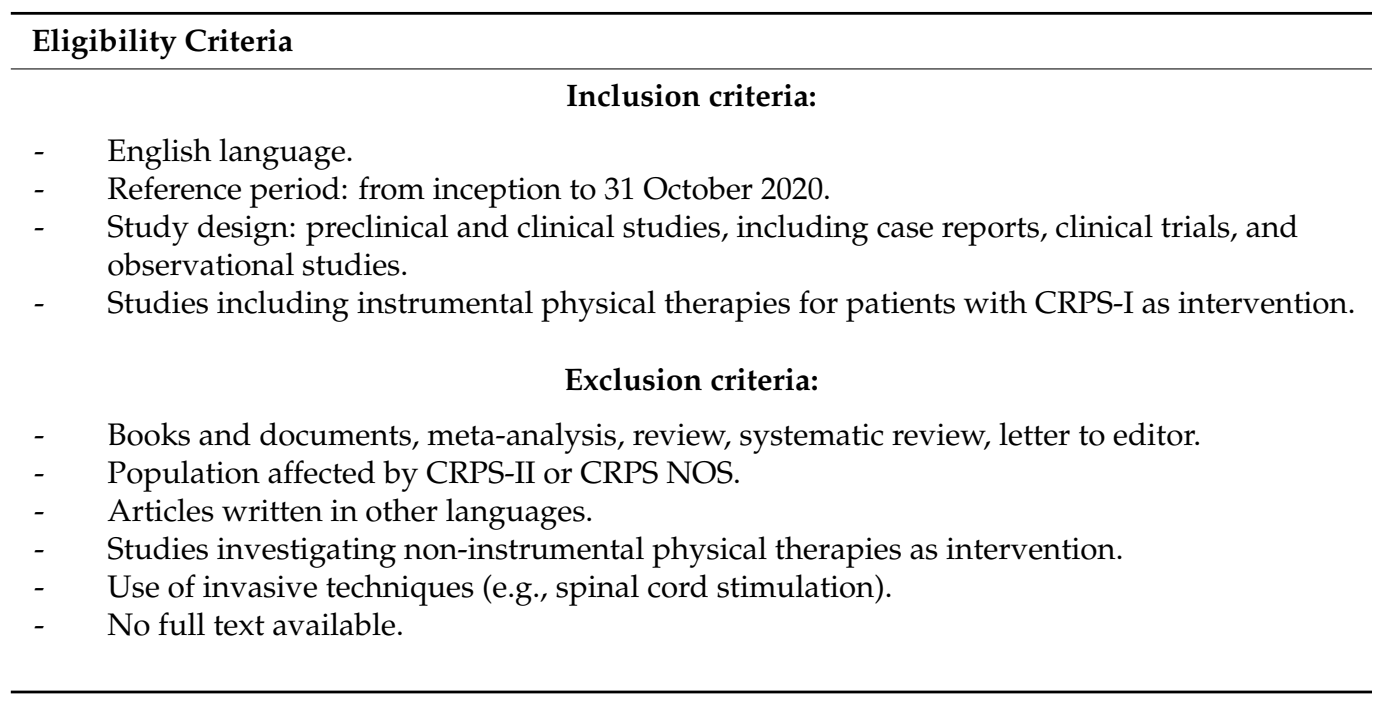

\section{Results}

Two hundred and nine items were initially found. One hundred sixty-four papers were excluded after title and abstract evaluation, according to exclusion criteria. Subsequently, full text assessment of the remaining 45 papers, led to the exclusion of other 35 studies because did not fulfill inclusion criteria. Finally, 10 articles published between 1983 and 2018 were selected in the current scoping review. In particular, we included three papers evaluating the efficacy and seven papers evaluating the effectiveness of physical therapy modalities in CRPS-I. Among selected studies, we found two papers regarding electromagnetic field therapy (one randomized double-blind, placebo-controlled and one randomized controlled double-blind pilot study); eight papers regarding patients receiving electrotherapy (one randomized, double-blinded, placebo-controlled prospective study; three case reports; three case series; one case-control study); two papers regarding laser therapy (one case control study; one case series). Among these papers, two studies (one case series and one case-control study) investigated the role of multiple interventions (i.e., transcutaneous electrical nerve stimulation (TENS) and laser therapy) in CRPS.

No preclinical studies were found. No studies about extracorporeal shockwave therapy, induced hyperthermia, or cryotherapy were found. In Figure 1, the selection process of the papers is presented.

In Tables 3 and 4, the characteristics and main findings of the included studies evaluating, respectively, the efficacy and the effectiveness of physical therapy modalities are presented.

\subsection{Electromagnetic Field Therapy}

In the current scoping review, we included two papers evaluating the efficacy of electromagnetic field therapy on CRPS-I.

Durmus et al. [17] performed a randomized double-blind placebo-controlled study evaluating the efficacy of pulsed electromagnetic field (PEMF) treatment, administered with calcitonin and exercise in terms of pain (measured by VAS score), swelling, bone scan and laboratory findings compared to calcitonin plus exercise administration. Forty patients with CRPS-I, developed after a Colles' fracture, were included. They received calcitonin and exercise treatment for 6 weeks. In addition to this treatment, 20 patients (group 1) received PEMF, and the other 20 (group 2) received a placebo (positioning of the same device switched off). No significant between-group difference was reported for all outcomes investigated.

More recently, Benedetti et al. [18] conducted a randomized controlled double-blind pilot study to investigate the efficacy of bio-electro-magnetic-energy-regulation (BEMER) 
magneto-therapy on 30 patients with CRPS-I. Two groups of 15 participants each were formed. Experimental group received rehabilitation program associated to BEMER therapy for 10 consecutive days while control group received the same rehabilitation program together with a sham BEMER treatment. Outcome measures were pain (measured by VAS), upper limb function (measured by hand grip strength and disabilities of the arm, shoulder, and hand scores) and lower limb function (measured by Maryland Foot Score). After a 1-month follow-up, patients treated with BEMER combined with rehabilitation program had statistically significant pain relief ( $50 \%$ vs. $9 \% ; p=0.002)$ and functional improvement both for upper $(46.7 \%$ vs. $31.8 \%$; $p=0.241)$ and lower limbs $(38.5 \%$ vs. $14.6 \% ; p=0.009)$ compared to control group.

\subsection{Electrotherapy}

Eight studies focused on the effects of electrotherapy on CRPS-I. One of them [19] compared the effects of laser therapy with electrotherapy, so its results are presented in the laser therapy section (Section 3.3).
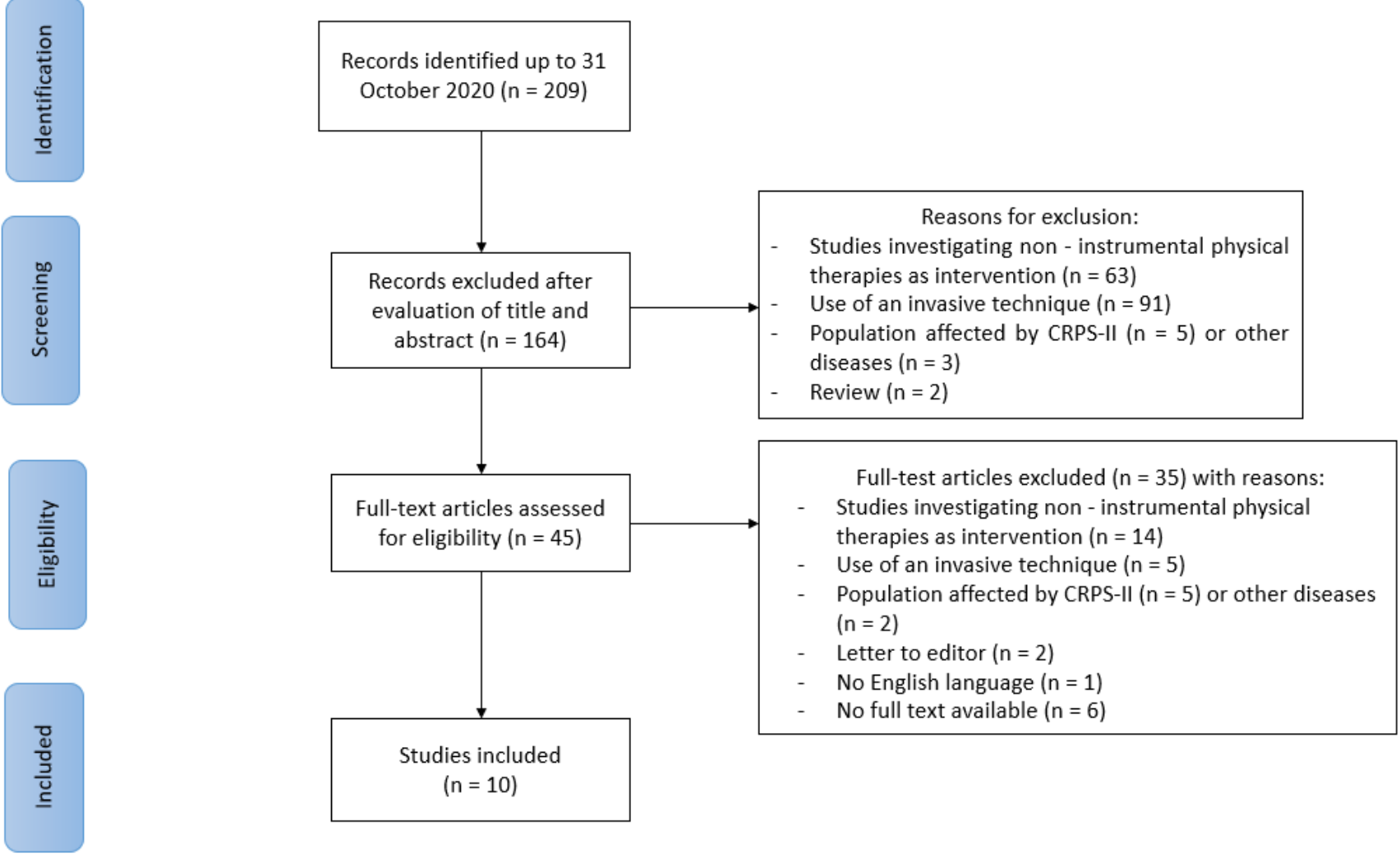

Studies included $(n=10)$

Figure 1. PRISMA-ScR flow chart for the study selection. CRPS: complex regional pain syndrome. 
Table 3. Characteristics and main findings of the included studies evaluating the efficacy of physical agent modalities.

\begin{tabular}{|c|c|c|c|c|c|}
\hline Author, Year & $\begin{array}{l}\text { Physical Therapy } \\
\text { Modality }\end{array}$ & Study Design & Sample Size: Total (group) & Administration & Main Findings \\
\hline $\begin{array}{c}\text { Durmus A. et al. } \\
2004\end{array}$ & PEMF & $\begin{array}{l}\text { Randomized double-blind, } \\
\text { placebo-controlled } \\
\text { study }\end{array}$ & $\begin{array}{c}n=40 \\
\text { PEMF Group: } n=20 \\
\text { Placebo Group: } n=20\end{array}$ & $\begin{array}{c}\text { Both groups: } \\
\text { Calcitonin (100 units ampoule for } 6 \text { weeks) and } \\
\text { active/active assistive ROM exercises (three times a day } \\
\text { for a period of } 30 \text { min per session for } 6 \text { weeks). } \\
\text { PEMFs: } \\
\text { intensity } 100 \text { Gauss, frequency } 50 \text { Hertz ( } 5 \text { times a week } \\
\text { for } 6 \text { weeks, } 30 \text { sessions). } \\
\text { Placebo treatment: device turned off } \\
\text { (60 min per session). }\end{array}$ & $\begin{array}{l}\text { No additional benefits were } \\
\text { observed to PEMFs associated to } \\
\text { calcitonin and exercise therapy in } \\
\text { improving pain (measured by } \\
\text { VAS score), swelling, } \\
\text { instrumental (bone scan), and } \\
\text { laboratory values. }\end{array}$ \\
\hline $\begin{array}{l}\text { Bilgili A. et al. } \\
2016\end{array}$ & TENS & $\begin{array}{l}\text { Randomized, double-blind, } \\
\text { placebo-controlled } \\
\text { prospective study }\end{array}$ & $\begin{array}{c}n=30 \\
\text { Experimental group } \\
\text { (conventional TENS + contrast bath }+ \\
\text { whirlpool bath }+ \text { exercise program) } \\
n=15 \\
\text { Control group } \\
\text { (sham TENS + contrast bath }+ \text { whirlpool } \\
\text { bath }+ \text { exercise program) } \\
n=15\end{array}$ & $\begin{array}{l}\text { Sharm TENS: device turned off. } \\
\text { 50-100 milliseconds. Duration: } 20 \text { min for session. } \\
\text { Contrast bath: immersion in hot water }\left(38^{\circ} \mathrm{C}\right) \text { for } 4 \mathrm{~min} \\
\text { followed by cold water }\left(4{ }^{\circ} \mathrm{C}\right) \text { for } 1 \text { min. Overall duration } \\
20 \text { min. } \\
\text { Whirlpool bath: immersion in a whirlpool tank containing } \\
\text { hot water }\left(37^{\circ} \mathrm{C}\right) \text { for } 15 \text { min. } \\
\text { Exercise program: daily active, active assistive and passive } \\
\text { ROM exercises ( } 3 \text { sets of } 10 \text { repeats for } 15 \text { sessions). } \\
\text { All interventions were administered for } 15 \text { sessions. } \\
\text { BEMER PEMFs: frequency < } 33.3 \text { Hertz, intensity (total } \\
\text { body: } 7-35 \text { microTesla, pad: } 60-100 \text { microTesla). Duration: } \\
\text { daily } 20 \text {-min session for } 10 \text { days. }\end{array}$ & $\begin{array}{l}\text { Additional TENS reduces } \\
\text { spontaneous pain (measured by } \\
\text { VAS), neuropathic pain } \\
\text { (measured by DN-4 and LANSS } \\
\text { scores), volumetric oedema, and } \\
\text { improves ROM. }\end{array}$ \\
\hline $\begin{array}{l}\text { Benedetti M.G. } \\
\text { et al. } 2018\end{array}$ & PEMF & $\begin{array}{l}\text { Randomized controlled } \\
\text { double-blind pilot study }\end{array}$ & $\begin{array}{c}n=30 \\
\text { Experimental group } \\
\text { (rehabilitation program + BEMER EMFs) } \\
N=15 \\
\text { Control group } \\
\text { (rehabilitation program + placebo BEMER } \\
\text { treatment) } \\
n=15\end{array}$ & $\begin{array}{c}\text { BEMER placebo treatment: } \\
\text { device turned off. } \\
\text { Rehabilitation program: information on the pathology, } \\
\text { contrast of kinesiophobia, } \\
\text { psychological support, } \\
\text { kinesiotherapy with active/active/assisted/passive } \\
\text { mobilization, desensitization } \\
\text { techniques, proprioceptive feedback, gait rehabilitation for } \\
\text { lower limb; perceptive motor therapy and occupational } \\
\text { therapy for upper limb. Duration: 2-h sessions per day, for } \\
10 \text { days. }\end{array}$ & $\begin{array}{l}\text { BEMER PEMFs combined with } \\
\text { other rehabilitation interventions } \\
\text { reduce pain (measured by VAS } \\
\text { score) and improves strength and } \\
\text { function (measured by HGS and } \\
\text { DASH scores for the upper limb } \\
\text { and by MFS for the lower limb) } \\
\text { in the short term (1 month). }\end{array}$ \\
\hline
\end{tabular}

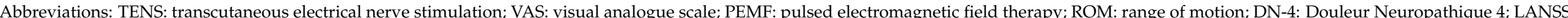

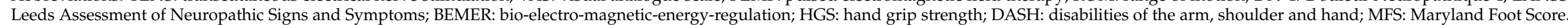


Table 4. Characteristics and main findings of the included studies evaluating the effectiveness of physical agent modalities.

\begin{tabular}{|c|c|c|c|c|c|}
\hline Author, Year & $\begin{array}{c}\text { Physical Therapy } \\
\text { Modality }\end{array}$ & $\begin{array}{c}\text { Study } \\
\text { Design }\end{array}$ & Sample Size: Total (Group) & Administration & Main Findings \\
\hline $\begin{array}{l}\text { Bohednim R. } \\
\text { et al. } 1983\end{array}$ & TENS & Case report & $n=1$ & $\begin{array}{c}\text { Pulse rate: } 20 \text { pulses per second } \\
\text { Width: } 100 \text { microseconds } \\
\text { Intensity depending on patient tolerance. } \\
\text { Duration: one hour, three times a week for } 2 \text { months. } \\
\text { TENS: no data available. }\end{array}$ & $\begin{array}{c}\text { TENS improved pain relief and stimulated weight } \\
\text { acceptance on the involved limb. There was an } \\
\text { increase in bone stock and atrophy resolution in a } \\
\text { short time. }\end{array}$ \\
\hline $\begin{array}{l}\text { Bukhalo J. et al. } \\
2004\end{array}$ & TENS & Case report & $n=1$ & $\begin{array}{l}\text { Naproxen: } 125 \mathrm{mg} \text { orally twice daily. } \\
\text { Physical therapy: massage using lymphedema } \\
\text { techniques of skin stretching, along with active and passive } \\
\text { range of motion exercises. Duration: } 3 \text { times a week. } \\
\text { TENS: high frequency (100 Hertz), pulse width } 150 \\
\text { milliseconds, } 4 \text { channels. }\end{array}$ & $\begin{array}{l}\text { TENS remarkably improved pain, swelling, and } \\
\text { oedema two weeks after the beginning of therapy. At } \\
1 \text { month, symptoms completely resolved. }\end{array}$ \\
\hline $\begin{array}{l}\text { Anandkumar S. } \\
\text { et al. } 2014\end{array}$ & TENS & Case report & $n=1$ & $\begin{array}{l}\text { Kinesio Tape: " } \mathrm{I} \text { " strips measuring } 15 \mathrm{~cm} \text { and } 25 \mathrm{~cm} \text { applied for } \\
\text { about } 48 \mathrm{~h} \text {. } \\
\text { PEPT: daily bi-manual activities such as cutting vegetables, etc. } \\
\text { Exercise therapy: scapular setting exercises using a Swiss ball } \\
\text { (10 times, } 3 \text { sets) and rotator cuff strengthening exercises using } \\
\text { a Thera-Band latex free resistance band (10 times, } 3 \text { sets). } \\
\text { Duration: } 8 \text { weeks. }\end{array}$ & $\begin{array}{l}\text { Intervention resolved pain (measured by VAS), } \\
\text { improved upper limb physical function (measured by } \\
\text { DASH) and kinesiophobia (measured by TSK) after } 7 \\
\text { weeks and maintained at six months. }\end{array}$ \\
\hline $\begin{array}{c}\text { Ashwal S. et al. } \\
1988\end{array}$ & TENS & Case series & $n=3$ & $\begin{array}{l}\text { Case 1: TENS (no data available). } \\
\text { Case 2: sympathectomy. } \\
\text { Case 3: TENS (no data available). }\end{array}$ & $\begin{array}{l}\text { Case 1: immediate decrease in hyperesthesia. } \\
\text { Symptoms resolved within } 3 \text { months. } \\
\text { Case 2: normal strength and sensation was achieved } \\
30 \text { months after initial symptoms. } \\
\text { Case 3: reduction of pain after } 5 \text { days. } \\
\text { Case 1: able to walk at discharge after } 2 \text { weeks. }\end{array}$ \\
\hline $\begin{array}{c}\text { Cimaz R. et al. } \\
1999\end{array}$ & $\begin{array}{l}\text { Electrotherapy } \\
\text { (TENS, electrical } \\
\text { stimulation), laser } \\
\text { therapy }\end{array}$ & Case series & $n=6$ & $\begin{array}{c}\text { Case 1: naproxen and physical therapy (passive movements). } \\
\text { Case 2: ganglion blockade, TENS (no data available), } \\
\text { psychotherapy. } \\
\text { Case 3: electrical stimulation (no data available), } \\
\text { psychotherapy, physical therapy, electrotherapy (no data } \\
\text { available). } \\
\text { Case 4: immobilization, laser therapy (no data available), local } \\
\text { injections, FANS, physical therapy. } \\
\text { Case 5: physiotherapy. } \\
\text { Case 6: acetaminophen and psychotherapy. }\end{array}$ & $\begin{array}{c}\text { Case 2: persistence of symptoms after two years, with } \\
\text { less severity and frequency. } \\
\text { Case 3: good results of electrical stimulation initially. } \\
\text { After } 8 \text { months patient had a conversion reaction } \\
\text { treated with psychotherapy, physical therapy, and } \\
\text { electrotherapy, with no benefits. } \\
\text { Case 4: no improvement reported. } \\
\text { Case 5: resolution of symptoms over time (not } \\
\text { specified). } \\
\text { Case 6: symptoms quickly improved (timing of } \\
\text { follow-up not specified). }\end{array}$ \\
\hline $\begin{array}{l}\text { Raucci U. et al. } \\
2016\end{array}$ & Scrambler therapy & Case series & $\begin{array}{l}\quad n=4 \\
\text { (3 patients had CRPS-I, one } \\
\text { patient had CRPS-II) }\end{array}$ & $\begin{array}{l}\text { A } 45 \text {-min daily treatment was administered to each patient } \\
\text { for } 10 \text { consecutive days. Intensity differed amongst patients } \\
\text { (maximum intensity without additional pain). }\end{array}$ & $\begin{array}{l}\text { Pain relief (measured by NRS) and improved quality } \\
\text { of life for long periods (not specified). }\end{array}$ \\
\hline
\end{tabular}


Table 4. Cont.

\begin{tabular}{|c|c|c|c|c|c|}
\hline Author, Year & $\begin{array}{c}\text { Physical Therapy } \\
\text { Modality }\end{array}$ & $\begin{array}{l}\text { Study } \\
\text { Design }\end{array}$ & Sample Size: Total (Group) & Administration & Main Findings \\
\hline $\begin{array}{l}\text { Karabegovic A. } \\
\text { et al. } 2009\end{array}$ & $\begin{array}{l}\text { Laser therapy, } \\
\text { electrotherapy } \\
\text { (TENS, stabile } \\
\text { galvanization) }\end{array}$ & $\begin{array}{l}\text { Case control } \\
\text { study }\end{array}$ & $\begin{array}{c}n=70 \\
\text { Experimental group } \\
\text { (kinesiotherapy and ice massage } \\
\text { plus laser therapy) } \\
n=35 \\
\text { Control group } \\
\text { (kinesiotherapy and ice massage } \\
\text { plus TENS and stabile } \\
\text { galvanization) } \\
n=35\end{array}$ & $\begin{array}{c}\text { Experimental group: } \\
\text { Infrared laser: } 830 \text { nanometres. } \\
\text { Dose: } 3 \text { Joule. } \\
\text { Mean power: } 50 \text { milliwatts } \\
\text { Control group: } \\
\text { TENS, stabile galvanization: No data available } \\
\text { Duration of treatments for both groups: } 6 \text { weeks. }\end{array}$ & $\begin{array}{l}\text { Laser therapy shows significantly better results in } \\
\text { reducing pain (measured by VAS score), swelling } \\
\text { (range measured by the centimetres band), disability } \\
\text { (DASH questionnaire), independence (Barthel index } \\
\text { and FIM) and in increasing ROM compared to TENS. }\end{array}$ \\
\hline
\end{tabular}

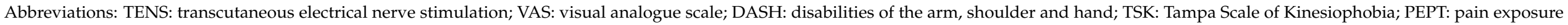
physical therapy; NRS: numeric rating scale; FIM: functional independence measurement; ROM: range of motion. 


\subsubsection{TENS}

A case report performed by Bohednim et al. [20] reported a Sudeck's atrophy resolution by the adjunctive use of TENS. The patient was a 43-year-old man with right distal tibia fracture and fibula contusion after falling off a ladder. The treatment consisted of the closed reduction of the fracture, and a cast. The patient was still unable to support weight on the right lower limb when the cast was removed due to pain and needed regular use of rescue pain drugs. Thirteen months after the injury, the patient received TENS for one hour a day, three times a week for 2 months. After one month, the patient reached full weight bearing with no cane needed anymore. At the end of treatment, the patient was able to move his right ankle in dorsal and plantar flexion, gradually reducing the use of pain medications. The patient returned at work after one month from the end of treatment.

Likewise, Bukhalo et al. [21] reported the case of a baby (3 years of age) affected by CRPS-I following a right ankle sprain and fall injury. A conservative treatment based on rest, elevation, ice, and ibuprofen brought no results after 3-4 weeks. Therefore, for three weeks his ankle and foot were then immobilized in a cast. After cast removal he recovered ankle full range of motion (ROM), but weight bearing pain persisted. He was prescribed oral naproxen $125 \mathrm{mg}$ twice a day and TENS. Physical therapy also included massage using lymphedema techniques of skin stretching, along with active and passive ROM exercises. Two weeks later, the patient had a considerable clinical improvement, and after 1 month, he totally recovered.

Similar results were reported by Anandkumar et al. [22], who described the case of a 48-year-old female who presented shoulder pain, hypersthesias and swelling of the hand after a cerebrovascular accident. Significant improvement of pain was achieved after three sessions of pain neurophysiology education. Later, TENS, kinesiotape application, "pain exposure" physical therapy and exercise therapy was administered for a period of 7 weeks. After 6 months, she still was pain -free.

Ashwal et al. [23] reported two cases of patients with CRPS-I treated with TENS. A girl 10 years of age started to feel a stabbing pain in her right foot with no previous trauma or injection. Symptoms persisted despite acetylsalicylic acid (ASA) treatment. The patient was treated with TENS and had an immediate improvement in terms of hyperesthesia. After 3 months, she completely recovered and she got a normal ambulation, despite a slight atrophy. The authors also reported the case of a girl 10 years of age that manifested pain and swelling of the right knee and ankle 3 weeks after an upper respiratory infection. The patient was treated with TENS, reducing pain and improving the ability to support weight on the right leg during the next 5 days.

Bilgili et al. [24] assessed the clinical recovery in thirty TENS-treated CRPS type 1 patients. Fifteen participants were randomly assigned to a group receiving standard TENS therapy for $20 \mathrm{~min}$, while 15 participants received sham TENS. Both groups received conventional physical therapy, consisting of $20 \mathrm{~min}$ of a contrast bath, $15 \mathrm{~min}$ of a whirlpool bath, ROM exercise of both assisted active and passive types, and stretching exercises from a static position until the patient felt pain. The intervention was scheduled for 15 sessions. The outcome measures were spontaneous pain (assessed by VAS), neuropathic pain (assessed by the Leeds Assessment of Neuropathic Signs and Symptoms Scale and the Douleur Neuropathique en 4 Questions), ROM (assessed by a goniometer) and edema (volumetric measurement). Hand grip strength was assessed using a hand dynamometer while activity limitations of the hand was evaluated with the Duruöz Hand Index (DHI). A significant reduction was reported for spontaneous and neuropathic pain scores and edema, and a significant improvement of ROM and functional capacity in both groups $(p<0.05)$. Group 1 showed a significantly greater improvement regarding pain intensity, neuropathic pain assessed using LANSS, edema, and in the second to third finger ROM measurements $(p<0.05)$. No significant between-group differences were found in terms of fourth to fifth finger and wrist ROM, hand grip strength, DN-4 and DHI scores.

Finally, in the six cases reported by Cimaz et al. [25], two cases of patients suffering from RSD were treated with electrotherapy. A 12-year-old girl with severe psychological 
disturbances developed swelling and pain in the right hand the day of her regular notspecified drug injection. She had to undergo ganglion blockade in hospital, but symptoms resolved for only about 20 days. Electrical stimulation together with psychotherapy was then attempted. Two years later, she still had symptoms, though they were less severe and less frequent. A 10 year-old girl developed severe pain in the right lower limb after a right tibial fracture. She had to use crutches for 2 months, then she recovered. There was a relapse of symptoms after one year and the girl was hospitalized. The parents did not accept treatment for their daughter with psychotherapy even though recommended. Initially, there was an improvement with electrical stimulation, but there was a conversion reaction (hysteria) involving her lower limbs 8 months later. No significant results were found with psychotherapy, physical therapy and electrotherapy.

\subsubsection{Scrambler Therapy}

A case series performed by Raucci et al. [26] evaluated the effectiveness, safety and durability of scrambler therapy in three patients with CRPS-I. There was no result, neither with conventional therapy nor the nonconventional one. Forty-five minutes of daily treatment were performed for each patient for 10 consecutive days. The intensity of the treatment was tailored, taking into account the patient's pain tolerability. Progressively, there was an improvement until the complete relief of neuropathic pain and return to normal daily activities after treatment.

\subsection{Laser (or Light) Therapy}

Two studies evaluated laser therapy in patients with CRPS-I. Karabegovic et al. [19] performed a case-control study comparing the effects of laser therapy with electrotherapy (TENS, stabile galvanization) on shoulder-hand syndrome after stroke. The participants were divided in experimental group $(n=35)$ who received laser therapy and control group $(n=35)$ treated with electrotherapy. Kinesis therapy and ice massage were administered in both groups. The outcome measures were VAS pain, DASH, Barthel index and FIM. Laser therapy showed better results than electrotherapy in reducing pain $(p<0.0001)$, swelling $(p<0.01)$, disability $(p<0.01)$ and in improvement of independency $(p<0.01)$.

In the case series of Cimaz et al. [25], the case of a boy 10 years of age was described, who was suffering from RSD involving the left foot after a trauma that was treated for 2 months with immobilization (casting), laser therapy, and local injections of not-specified agents, without improvement. Subsequently, nonsteroidal anti-inflammatory drugs and physical therapy were administered. A rapid improvement of symptoms was reported after resuming weight bearing and ambulation. No relapse was reported.

\section{Discussion}

To the best of our knowledge, this is the first study evaluating the efficacy and effectiveness of physical agent modalities in patients with CRPS-I. Although these treatments are widely available in clinical practice, scientific evidence in favor of their application for the management of CRPS-I is poor.

CRPS-I is a painful and long-lasting condition that needs to be properly defined, diagnosed and treated in order to diminish its negative implications on functioning and quality of life [27]. Phenotypic and pathogenetic complexity makes it difficult to define an operational approach that is easily applicable in clinical practice. To prevent the risk of serious complications that lead to chronic pain, functional limitations and disability, a timely and appropriate pharmacological intervention should be started at the onset of symptoms. Moreover, non-pharmacological treatments, such as physical therapy and cognitive behavioral therapy, should be combined with drug therapy, and might be particularly useful in the late stages of CRPS-I, where a multimodal approach is more adequate to prevent psycho-emotional and socioeconomic implications [28]. However, evidence about the effectiveness of multimodal physiotherapy, including instrumental physiotherapy, for treating people with CRPS-I is usually lacking or unclear [29]. 
Our data confirm the role of physical modalities, in particular electrotherapy and PEMF, as useful treatments when combined with other interventions for CRPS-I.

According to international guidelines, TENS is recommended for pain treatment in patients with CRPS-I [10]. TENS reduces pain through the enhancement of the gate control mechanism [30], the promotion of brain endorphin release and the local modulation of vascular tone in injured tissues [31]. However, evidence about its role in the management of CRPS-I is still debated. There is only one RCT [24] supporting the efficacy of TENS in combination with therapeutic exercise in improving ROM and reducing pain and oedema in CRPS type I patients. According to the observational studies [20-23,25] included in our scoping review, we found data about heterogeneous populations as well as low quality of evidence. Indeed, some studies $[21,23,25]$ included children and only two studies included adults [20,22]. Starting an early TENS treatment (within 3 months from diagnosis) seems to provide best chance of recovery for children with CRPS-I [21,23]. In the same population, TENS was administered as a single intervention following the failure of other conservative treatments [21,23] while in adults, this approach was started after cast removal [20] or as a part of a multimodal treatment [22]. However, these empirical but anecdotal findings require confirmation in further rigorous studies. TENS is a safe and simple to use procedure to manage pain in children, but its use is contraindicated in patients with pacemakers, epilepsy, metal implants, and poor sensation. A continuous setting, between 70 and 120 Hertz and between 70 and 120 milliseconds pulse duration is recommended when TENS is used on a child for the first time [32]. Regarding TENS parameters such as frequency, pulse width, duration and numbers of sessions, used in adults with CRPS-I in the studies included, there is a large variability. A detailed treatment protocol was reported only by Bilgili et al. [24] that demonstrated the efficacy of a daily application, for a total of 15 sessions, of TENS administered for $20 \mathrm{~min}, 100$ Hertz frequency, 50-100 milliseconds pulse duration. Considering these uncertain results, future research is required to establish a standardized protocol treatment in patient with CRPS-I.

One study investigated the effectiveness of scrambler therapy in patients with neuropathic pain associated to CRPS-I [26]. It has been hypothesized that this intervention interacts with $\mathrm{C}$ fiber surface receptors replacing pain information with synthetic "non pain" information [33]. This intervention could play a role in CRPS-I patients unresponsive to previous pharmacological and non-pharmacological approaches. However, the very low quality of evidence does not allow one to draw reliable conclusions about its role in patients with CRPS-I and future research is needed.

In CRPS-I patients, PEMF seems to have benefits on both pain and inflammation [34]. Cells biostimulation induced by PEMF helps to restore the physiological electrical charge reactivating tissue self-healing process [35]. However, our results on the effect of PEMF on CRPS-I are controversial. While Durmus et al. [17] did not report a difference between PEMF therapy and the placebo in reducing pain after 6 weeks, a more recent study conducted by Benedetti et al. [18] reported a significant improvement administering BEMER treatment for pain, strength and function after 1 month. Positive results obtained using BEMER therapy could be due to its marked effects on microcirculation. This therapy applies the specifically developed BEMER signal patterns with effects on microvessels, and consequently on arteriolar and venular flow volume [36]. This mechanism of action might counteract increased vasoconstriction, tissue hypoxia, and metabolic tissue acidosis that impair microcirculation during chronic stage of CRPS-I [37].

Laser therapy has analgesic and anti-inflammatory effects and seems to modulate the sympathetic tone that might result in clinical benefits in CRPS-I treatment [38]. However, its mechanism on pain relief is not completely understood. Several mechanisms have been proposed, such as increased endogenous opioid production, enhanced local blood circulation, increased oxygen consumption, increased adenosine triphosphate (ATP) and anti-inflammatory cytokines production in exposed cells [39]. Observational data suggest that laser therapy is more effective than electrotherapy for pain relief and the reduction of swelling and disability [19] in patients who developed CRPS-I after a stroke. It should be 
supposed that this finding can be referred to improved energy metabolism and enhanced cell viability promoted by laser therapy [40]. However, future research is needed to confirm these results. As for children, evidence about laser therapy use for CRPS-I is very scant. We found a single case report [25] describing a 10-year-old boy with CRPS-I treated with laser therapy that did not provide any improvement of symptoms. Moreover, it should be underlined that the administration of laser therapy in development stages of life is controversial due to possible negative effects on bone growth plates [41].

\section{Limitations}

Our study has several limitations. First, our scoping review collects information from a broad spectrum of study designs and methods, without an accurate evaluation of the quality of evidence. Most of included studies are observational studies with a very low quality of evidence (mostly case reports and case series, no cohort studies). A limited number of RCTs, the heterogeneity of the proposed treatments (combining instrumental therapy with different physical exercise protocol and drugs) and the lack of detailed descriptions regarding intervention (duration and treatment parameters) do not allow us to reach definite conclusions. Second, only three studies $[18,22,26]$ diagnosed CRPS-I according to Budapest criteria, while others did not clearly report the diagnostic criteria. Third, the outcome measures assessed in the included studies are very heterogeneous. Most of the available research about CRPS-I treatment with physical modalities focused on pain as the main outcome assessed by unidimensional tools, such as VAS and NRS. However, these outcome measures investigated the intensity of pain only, without evaluating qualitative aspects. Some authors $[18,22,24,27]$ used more specific scores, such as DN-4 and LANSS scores (for neuropathic pain). Moreover, few studies analyzed functional outcomes such as muscle strength (HGS), upper and lower limb function (DASH and MFS), kinesiophobia (TSK), and independence (Barthel index and FIM), albeit not specific for CRPS-I. Finally, all studies failed to detail the ethics approval and only four studies reported the acquisition of informed consent $[18,22,24,26]$. Only in three studies $[18,22,24]$ did authors declare that they had no conflict of interest.

\section{Conclusions}

CRPS-I is a multifactorial disease characterized by pain, reduced function and poor quality of life. Physical therapy modalities are usually included in common clinical practice, but evidence about their effectiveness and efficacy is limited. Moreover, instrumental physical modalities, except TENS, are not recommended for the management of CRPS-I. However, the combination of different therapeutic modalities was proposed to manage this condition. Our study evaluated the scientific literature available to verify if the empirical use of these techniques has scientific support.

Our data suggest that including physical therapy modalities, such as TENS, PEMF or laser, in rehabilitation programs, may contribute to reduce pain and improve function in patients with CRPS-I.

However, future research should provide adequate details about the parameters and timing of different physical therapy modalities to provide a standardized clinical protocol. Since no studies investigating extracorporeal shockwave therapy, induced hyperthermia, and cryotherapy were found, future research is required. Taking into account the low incidence of CRPS-I, multicenter RCTs are desirable in order to investigate a homogeneous larger sample population and provide a better quality of evidence.

Author Contributions: Conceptualization, A.M. and G.I.; methodology, M.A., S.C., M.P., G.T., S.L., and F.G.; writing—original draft preparation, A.M., G.I., M.A., M.P., G.T., and S.L.; writing—review and editing, M.P., G.T., S.L., and F.G.; supervision, A.M., and G.I.. All authors have read and agreed to the published version of the manuscript.

Funding: This research received no external funding.

Institutional Review Board Statement: Not applicable. 
Informed Consent Statement: Not applicable.

Data Availability Statement: Not applicable.

Conflicts of Interest: The authors declare no conflict of interest.

\section{References}

1. Harden, R.N.; Bruehl, S.; Galer, B.S.; Saltz, S.; Bertram, M.; Backonja, M.; Gayles, R.; Rudin, N.; Bhugra, M.K.; Stanton-Hicks, M. Complex regional pain syndrome: Are the IASP diagnostic criteria valid and sufficiently comprehensive? Pain 1999, 83, $211-219$. [CrossRef]

2. Marinus, J.; Moseley, G.L.; Birklein, F.; Baron, R.; Maihöfner, C.; Kingery, W.S.; van Hilten, J.J. Clinical features and pathophysiology of complex regional pain syndrome. Lancet Neurol. 2011, 10, 637-648. [CrossRef]

3. Ott, S.; Maihöfner, C. Signs and Symptoms in 1043 Patients with Complex Regional Pain Syndrome. J. Pain 2018, 19, 599-611. [CrossRef] [PubMed]

4. Pergolizzi, J.V.; LeQuang, J.A.; Nalamachu, S.; Taylor, R.; Bigelsen, R.W. The Budapest criteria for complex regional pain syndrome: The diagnostic challenge. Anaesthesiol. Clin. Sci. Res. 2018, 2, 1-10. [CrossRef]

5. Mayo Clinic. Complex Regional Pain Syndrome-Symptoms and Causes. Available online: https://www.mayoclinic.org/ diseases-conditions / crps-complex-regional-pain-syndrome/symptoms-causes/syc-20371151 (accessed on 3 December 2020).

6. Merskey, H.; Addison, R.G.; Beric, A.; Blumberg, H.; Bogduk, N.; Boivie, J.; Bond, M.R.; Bonica, J.J.; Boyd, D.B.; Deathe, A.B.; et al. Classification of Chronic Pain: Descriptions of Chronic Pain Syndromes and Definitions of Pain Terms, 2nd ed.; Merskey, H., Bogduk, N., Eds.; IASP Press: Seattle, DC, USA, 1994; pp. 40-43.

7. Pons, T.; Shipton, E.A.; Williman, J.; Mulder, R.T. Potential risk factors for the onset of complex regional pain syndrome type 1: A systematic literature review. Anesthesiol. Res. Pract. 2015, 2015, 1-15. [CrossRef] [PubMed]

8. Urits, I.; Shen, A.H.; Jones, M.R.; Viswanath, O.; Kaye, A.D. Complex Regional Pain Syndrome, Current Concepts and Treatment Options. Curr. Pain Headache Rep. 2018, 22, 10. [CrossRef]

9. Harden, N.R.; Bruehl, S.; Perez, R.S.G.M.; Birklein, F.; Marinus, J.; Maihofner, C.; Lubenow, T.; Buvanendran, A.; Mackey, S. Validation of proposed diagnostic criteria (the "Budapest Criteria") for Complex Regional Pain Syndrome. Pain 2010, 150, 268-274. [CrossRef]

10. Royal College of Physichians. Complex Regional Pain Syndrome in Adults (2nd Edition), UK Guidelines for Diagnosis, Referral and Management in Primary and Secondary Care. 2018. Available online: https:/ /www.rcplondon.ac.uk/guidelines-policy/ complex-regional-pain-syndrome-adults (accessed on 3 December 2020).

11. Vescio, A.; Testa, G.; Culmone, A.; Sapienza, M.; Valenti, F.; Di Maria, F.; Pavone, V. Treatment of Complex Regional Pain Syndrome in Children and Adolescents: A Structured Literature Scoping Review. Children 2020, 7, 245. [CrossRef] [PubMed]

12. Daly, A.E.; Bialocerkowski, A.E. Does evidence support physiotherapy management of adult Complex Regional Pain Syndrome Type One? A systematic review. Eur. J. Pain 2009, 13, 339-353. [CrossRef]

13. Rakel, B.; Barr, J.O. Physical modalities in chronic pain management. Nurs. Clin. North Am. 2003, 38, 477-494. [CrossRef]

14. Maher, C.G. Effective physical treatment for chronic low back pain. Orthop. Clin. North Am. 2004, 35, 57-64. [CrossRef]

15. Ferronato, L.; Cunha, H.M.; Machado, P.M.; Souza, G.D.; Limana, M.D.; Avelar, N.C. Phisical modalities on the functional performance in knee osteoarthritis: A sytematic review. Fisioter. Mov. 2017, 30, 607-623. [CrossRef]

16. Tricco, A.C.; Lillie, E.; Zarin, W.; O’Brien, K.K.; Colquhoun, H.; Levac, D.; Moher, D.; Peters, M.D.; Horsley, T.; Weeks, L.; et al. PRISMA Extension for Scoping Reviews (PRISMA-ScR): Checklist and Explanation. Ann. Intern. Med. 2018, 169, 467-473. [CrossRef]

17. Durmus, A.; Cakmak, A.; Disci, R.; Muslumanoglu, L. The efficiency of electromagnetic field treatment in Complex Regional Pain Syndrome Type I. Disabil. Rehabil. 2004, 26, 537-545. [CrossRef] [PubMed]

18. Benedetti, M.G.; Cavazzuti, L.; Mosca, M.; Fusaro, I.; Zati, A. Bio-Electro-Magnetic-Energy-Regulation (BEMER) for the treatment of type I complex regional pain syndrome: A pilot study. Physiother. Theory Pract. 2018, 36, 498-506. [CrossRef] [PubMed]

19. Karabegović, A.; Kapidzić-Duraković, S.; Ljuca, F. Laser therapy of painful shoulder and shoulder-hand syndrome in treatment of patients after the stroke. Bosn. J. Basic Med. Sci. 2009, 9, 59-65. [CrossRef] [PubMed]

20. Bodenheim, R.; Bennett, J.H. Reversal of a Sudeck's atrophy by the adjunctive use of transcutaneous electrical nerve stimulation. A case report. Phys. Ther. 1983, 63, 1287-1288. [CrossRef]

21. Bukhalo, Y.; Mullin, V. Presentation and Treatment of Complex Regional Pain Syndrome Type 1 in a 3-Year-Old. Anesthesiology 2004, 101, 542-543. [CrossRef]

22. Anandkumar, S.; Manivasagam, M. Multimodal physical therapy management of a 48-year-old female with post-stroke complex regional pain syndrome. Physiother. Theory Pract. 2014, 30, 38-48. [CrossRef] [PubMed]

23. Ashwal, S.; Tomasi, L.; Neumann, M.; Schneider, S. Reflex sympathetic dystrophy syndrome in children. Pediatr. Neurol. 1988, 4, 38-42. [CrossRef]

24. Bilgili, A.; Çakır, T.; Doğan, Ş.K.; Erçalık, T.; Filiz, M.B.; Toraman, F. The effectiveness of transcutaneous electrical nerve stimulation in the management of patients with complex regional pain syndrome: A randomized, double-blinded, placebocontrolled prospective study. J. Back Musculoskelet. Rehabil. 2016, 29, 661-671. [CrossRef] 
25. Cimaz, R.; Matucci-Cerinic, M.; Zulian, F.; Falcini, F. Reflex Sympathetic Dystrophy in Children. J. Child. Neurol. 1999, 14, $363-368$. [CrossRef]

26. Raucci, U.; Tomasello, C.; Marri, M.; Salzano, M.; Gasparini, A.; Conicella, E. Scrambler Therapy $\left({ }^{\circledR}\right)$ MC-5A for Complex Regional Pain Syndrome: Case Reports. Pain Pract. 2016, 16, 103-109. [CrossRef] [PubMed]

27. de Sire, A.; Paoletta, M.; Moretti, A.; Brandi, M.L.; Iolascon, G. Complex regional pain syndrome: Facts on causes, diagnosis and therapy. Clin. Cases Miner. Bone Metab. 2018, 15, 166-172. [CrossRef]

28. Iolascon, G.; Moretti, A. Pharmacotherapeutic options for complex regional pain syndrome. Expert Opin. Pharmacother. 2019, 20, 1377-1386. [CrossRef] [PubMed]

29. Smart, K.M.; Wand, B.M.; O'Connell, N.E. Physiotherapy for pain and disability in adults with complex regional pain syndrome (CRPS) types I and II. Cochrane Database Syst. Rev. 2016, 2, CD010853. [CrossRef]

30. Tashani, O.; Johnson, M. Transcutaneous Electrical Nerve Stimulation (TENS) A Possible Aid for Pain Relief in Developing Countries? Libyan J. Med. 2009, 4, 62-65. [CrossRef]

31. Köke, A.J.; Schouten, J.S.; Lamerichs-Geelen, M.J.; Lipsch, J.S.; Waltje, E.M.; van Kleef, M.; Patijn, J. Pain reducing effect of three types of transcutaneous electrical nerve stimulation in patients with chronic pain: A randomized crossover trial. Pain 2004, 108, 36-42. [CrossRef] [PubMed]

32. Great Ormond Street Hospital for Children NHS Foundation Trust. Pain Relief Using Transcutaneous Electrical Nerve Stimulation (TENS). Available online: https:/ / www.gosh.nhs.uk/conditions-and-treatments/procedures-and-treatments/pain-relief-usingtranscutaneous-electrical-nerve-stimulation-tens (accessed on 21 December 2020).

33. Marineo, G. Inside the Scrambler Therapy, a Noninvasive Treatment of Chronic Neuropathic and Cancer Pain: From the Gate Control Theory to the Active Principle of Information. Integr. Cancer Ther. 2019, 18, 1534735419845143. [CrossRef]

34. Pagani, S.; Veronesi, F.; Aldini, N.N.; Fini, M. Complex Regional Pain Syndrome Type I, a Debilitating and Poorly Understood Syndrome. Possible Role for Pulsed Electromagnetic Fields: A Narrative Review. Pain Physician 2017, 20, E807-E822.

35. Markov, M.S. Magnetic Field Therapy: A Review. Electromagn. Biol. Med. 2007, 26, 1-23. [CrossRef] [PubMed]

36. Smith, T.L.; Wong-Gibbons, D.; Maultsby, J. Microcirculatory effects of pulsed electromagnetic fields. J. Orthop. Res. 2004, 22, 80-84. [CrossRef]

37. Groeneweg, G.; Huygen, F.J.; Coderre, T.J.; Zijlstra, F.J. Regulation of peripheral blood flow in complex regional pain syndrome: Clinical implication for symptomatic relief and pain management. BMC Musculoskelet. Disord. 2009, 10. [CrossRef] [PubMed]

38. Ide, Y. Phototherapy for chronic pain treatment. Masui 2009, 58, 1401-1406. [PubMed]

39. Huang, Z.; Ma, J.; Chen, J.; Shen, B.; Pei, F.; Kraus, V.B. The effectiveness of low-level laser therapy for nonspecific chronic low back pain: A systematic review and meta-analysis. Arthritis Res. Ther. 2015, 17, 360. [CrossRef]

40. Farivar, S.; Malekshahabi, T.; Shiari, R. Biological effects of low level laser therapy. J. Lasers Med. Sci. 2014, 5, 58-62.

41. De Andrade, A.R.; Meireles, A.; Artifon, E.L.; Brancalhão, R.M.C.; Ferreira, J.R.L.; Bertolini, G.R.F. The Effects of Low-Level Laser Therapy, 670 nm, on Epiphyseal Growth in Rats. Sci. World J. 2012, 1-5. [CrossRef] 